\title{
THE QUANTITATIVE STUDY OF POPULATIONS IN THE LEPIDOPTERA
}

2. MANIOLA JURTINA L.

W. H. DOWDESWELL

Science Department, Blundell's School, Tiverton

R. A. FISHER, F.R.S.

Department of Genetics, Combridge

E. B. FORD, F.R.S.

University Museum, Oxford

Received 10.v.48

1. Introduction

2. Material

3. Locality

4. Interchange between colonies, and variability

5. Migration

6. Numerical analysis of three populations of $M$. jurtina

7. Discussion

8. Summary

9. References

\section{INTRODUCTION}

ON a previous occasion (I), the present authors showed that an isolated population of Lepidoptera (Polyommatus icarus, Rott.) provided particularly suitable material for quantitative study, and that by adopting a system of marking and releasing, the numerical density could be calculated from the proportion of marked specimens subsequently recaptured. Moreover, it is possible to construct a life-table for the insects comprising such a population, and to determine whether it agrees with any given daily elimination-rate, (2). This may be a constant one, or the proportion eliminated may differ from one age-group to another.

Now it frequently happens, as we in fact found, that a community becomes subdivided into a number of smaller colonies by minor ecological barriers. In such circumstances, it is clearly desirable to determine quantitatively the extent to which leakage occurs between one inhabited area and the next. This aspect of animal movement is one which tends frequently to be overlooked, although it represents the normal condition found in most communities. In contrast, the occurrence of migration, to which so much study has been devoted, must be regarded as an abnormal and special phase to which, even in the most migratory animals, only a small part of their total life is committed. The method of marking by dots of cellulose paint, 
differing in colour and position, which we have adopted is well fitted to detect such leakage from one to another neighbouring colony. For the individuals in each may be given distinguishing marks in addition to those used to indicate dates of capture.

These various lines of approach open up a possibility of considerable ecological and evolutionary interest. That of measuring and comparing survival-rate in different colonies of known size, between which the amount of interchange can be determined.

With this object in view, two of us (W.H.D. and E.B.F.) spent the period 14th August to 3 rd September 1946 on the uninhabited island of Tean, Isles of Scilly. We wish to express our thanks to Major A. A. Dorrien-Smith for his kind permission to camp there.

\section{MATERIAL}

Our previous experience on Tean in 1938 led us to select the butterfly Maniola jurtina L. as suitable material for this study, and the choice proved to be justified. It is abundant on the island so that we were able to capture adequate samples without difficulty. Indeed, it seldom took the two of us more than an hour and a half to collect our full daily quota of 120 specimens. Furthermore, it is large enough to be handled easily during the work of marking and recording.

Perhaps its greatest advantage from our point of view is its willingness to fly in almost any kind of weather. At temperatures of $60^{\circ} \mathrm{F}$. and above, it is active even in the rain and without sunshine. Below this temperature it tends to become sluggish and requires a good deal of rousing. Only a strong wind combined with a low temperature rendered collecting impossible. This characteristic was a great asset not only in obtaining our sample but also because of the speed with which marked specimens redistributed themselves within the population when released. Thus we found that two hours of sunshine or even of warm dull weather were quite sufficient for randomisation to occur. Another valuable quality of this species is its freedom from large-scale migration, a feature which we tested experimentally (see section 4). Moreover, it tends to become restricted to certain well defined areas within its range. We only found it where the grass was long, and this was limited to places where gorse, bracken, and bramble protected it from grazing by a few cattle generally kept on the island and from strong winds and salt spray. Elsewhere there was a growth of short turf unsuitable for colonisation by $M$. jurtina.

\section{LOCALITY}

In our previous study of Polyommatus icarus (l.c.) we found that the island of Tean could be divided into a number of distinct regions. Those over which we collected were populated by the butterfly while 
the remainder were either shut off by effective barriers or covered by such vegetation as to prevent colonisation by that species. As already indicated, the distribution of $M$. jurtina is similarly localised but, owing to its different habits, the barriers and habitats are approximately reversed. Thus two areas in which we had previously met with $P$. icarus abundantly proved to be formidable barriers to M. jurtina.

We found that the island could conveniently be divided into five regions (see fig. I, map). Of these, I, 3, amd 5 are colonised by $M$. jurtina while 2 and 4 are not. In each of the three collecting areas, we chose a central point at which all the insects captured in it were released after marking. Exceptions to this procedure were instances

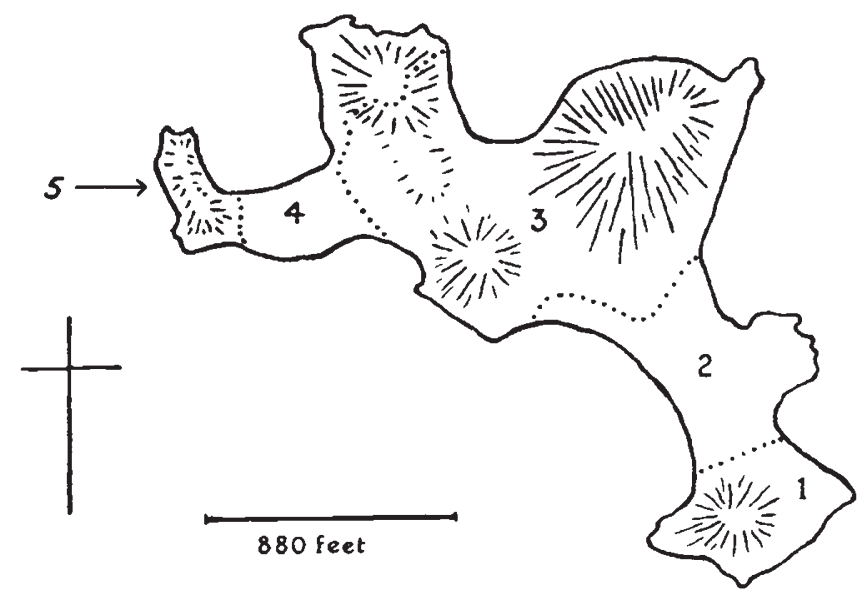

Fig. 1.-Tean (Isles of Scilly). Boundaries of collecting areas ......

in which butterflies had strayed from one area and been recaptured in another (see section 4). On such occasions they were liberated, after appropriate marking, in the area from which they had originally come.

Area I comprises about one third of the southern limb of the island. At its extremity is a small hill, about $5^{\circ}$ feet high, most of which is covered with a dense growth of bracken, bramble, and gorse. Interspersed with this are patches of long grass of various species, which are the favourite habitats of $M$. jurtina. Near the shore, and also to the north, the ground becomes more wind-swept, the bracken diminishes, while bramble and gorse disappear altogether. Associated with this change is a reduction in the quantity of long grass and hence in the number of $M$. jurtina. Area 2, which comprises the northern part of the southern limb of the island, is completely wind-swept and covered only with short stunted grass and a number of the hardier seaside plants such as Armeria maritima and Erythraea centaurium. It is not colonised by $M$. jurtina but forms an effective 
barrier between areas $\mathrm{I}$ and 3. Area 3 comprises the main body of the island and includes three hills, of which that to the north east is the highest (about 120 feet). For the most part it is covered with a dense growth of bracken, bramble, and long grass. On the slopes, however, bracken and bramble tend to be replaced by gorse, while on the summits there is little but stunted grass and a carpet of Calluna vulgaris and Erica cinerea. On the whole, area 3 is densely populated by $M$. jurtina. Area 4 is very similar in appearance to area 2 and includes the greater part of the western limb of the island, thus forming a barrier between areas 3 and 5 . Area 5 consists of a small promontory at the extremity of this western limb. This is formed by a mound about 30 feet high on whose eastern side are several patches of bracken and long grass, also a few stunted bramble bushes. This restricted area supports a small colony of the butterfly.

The distribution of M.jurtina on Tean in relation to the topography of the island thus presents the following compact ecological picture : a relatively large central massif (area 3 ), heavily populated and separated by barriers (areas 2 and 4 ) from two much smaller regions both supporting populations whose relative density does not differ greatly from that in area 3. One of these (area r) is situated at the southern, and the other (area 5), which is the smallest of all, at the western extremity of the island.

\section{INTERCHANGE BETWEEN COLONIES, AND VARIABILITY}

We were anxious to determine the amount of interchange between the three colonies of $M$. jurtina on Tean. Consequently, each specimen captured was (in addition to its date-marks, see section 5) distinguished so as to show the area in which it had first been caught. The base of the left hind wing on the underside was marked with a dot of white cellulose paint for area 3 and with a dot of blue for area 5 while it was left unmarked if the specimen had been taken in area $\mathrm{I}$ (that such an individual was a recapture was of course shown by a dot of paint on some other part of the wings, indicating the date on which it had been taken previously).

During our stay on Tean we recaught in all 183 specimens (99 females, 84 males) which we had previously marked, counting multiple recaptures of the same individual separately. That is to say: 68 (34 females, 34 males) in area 1,29 ( 14 females, 15 males) in area 3, and 86 ( $5 \mathrm{I}$ females, 35 males) in area 5 . Of this total of 183 , only three were recaptured in an area difierent from that in which they had previously been taken, together with an additional specimen (not included in the totals) which was found flying in the middle of a barrier (area 4), half way between areas 3 and 5 . The details of these four specimens are given in table $\mathrm{I}$.

It appears therefore that the amount of interchange from one colony to another on Tean was small and that the minor ecological barriers presented by areas 2 and 4 are rather effective. 
Consequently it seemed worth while to measure some variable character which could be used in comparing the populations from

TABLE I

Specimens of M. jurtina caught in one area and recaptured in another

\begin{tabular}{|l|c|c|c|c|}
\hline Previous captures & Original area & Recapture & New area & Sex \\
\cline { 5 - 5 } & & & & \\
\hline 18, viii & 1 & 23, viii & 3 & Female \\
20 & 5 & 23 & 3 & Male \\
24,27, viii & 3 & 25, ix & 5 & Female \\
25,27 & 4 & Female \\
\hline
\end{tabular}

our three areas in order to test whether isolation had caused them to evolve differently. We were handicapped in our choice since we were limited to features which could be studied on a living insect without risk of damaging it. We therefore decided to record the number of spots on the underside of the hind wings, scoring also the sexes. These spots vary from o to 5 on each hind wing, and it may reasonably be thought that they are under multifactorial control : a type of variation likely to respond relatively quickly to the effects of selection.

The numerical data which we obtained are given in table 2.

TABLE 2

Numbers of spots per hind wing of Maniola jurtina from three colonies on Tean, 1946

\begin{tabular}{|c|c|c|c|c|c|c|c|c|}
\hline \multirow{3}{*}{ Spot numbers } & \multicolumn{4}{|c|}{ Males } & \multicolumn{4}{|c|}{ Females } \\
\hline & \multicolumn{3}{|c|}{ Areas } & \multirow{2}{*}{ Totals } & \multicolumn{3}{|c|}{ Areas } & \multirow{2}{*}{ Totals } \\
\hline & I & III & V & & I & III & V & \\
\hline $\begin{array}{l}0 \\
1 \\
2 \\
3 \\
4 \\
5\end{array}$ & $\begin{array}{r}10 \\
34 \\
115 \\
41 \\
11 \\
\ldots\end{array}$ & $\begin{array}{r}11 \\
47 \\
203 \\
45 \\
12 \\
2\end{array}$ & $\begin{array}{r}2 \\
6 \\
21 \\
7 \\
2 \\
\ldots\end{array}$ & $\begin{array}{r}23 \\
87 \\
339 \\
93 \\
25 \\
2\end{array}$ & $\begin{array}{r}63 \\
52 \\
92 \\
34 \\
10 \\
3\end{array}$ & $\begin{array}{r}82 \\
73 \\
145 \\
55 \\
10 \\
1\end{array}$ & $\begin{array}{r}25 \\
29 \\
39 \\
12 \\
4 \\
\ldots\end{array}$ & $\begin{array}{r}170 \\
154 \\
276 \\
101 \\
24 \\
4\end{array}$ \\
\hline Totals. & 211 & $3^{20}$ & $3^{8}$ & 569 & 254 & 366 & 109 & 729 \\
\hline
\end{tabular}

They do not indicate that the three populations differ in the number of these spots. Either isolation had not caused the populations to diverge in this respect or else the numbers were too small to detect the change. However, there is a remarkable and fairly consistent difference between the distribution of these spots in the two sexes, 
to which attention should be drawn (fig. 2). It will be observed that each sex has a mode at two spots, but that, while the distribution is approximately symmetrical in the male, it is of an unusual kind in the female. For the higher numbers of spots the fall in frequency is approximately similar in the two sexes, but for the lower the female distribution becomes bimodal. Relatively more females than males have one spot, and this difference is so much increased for those which are spotless that such females are actually more numerous than are those in the one-spotted class. It looks as if more than one

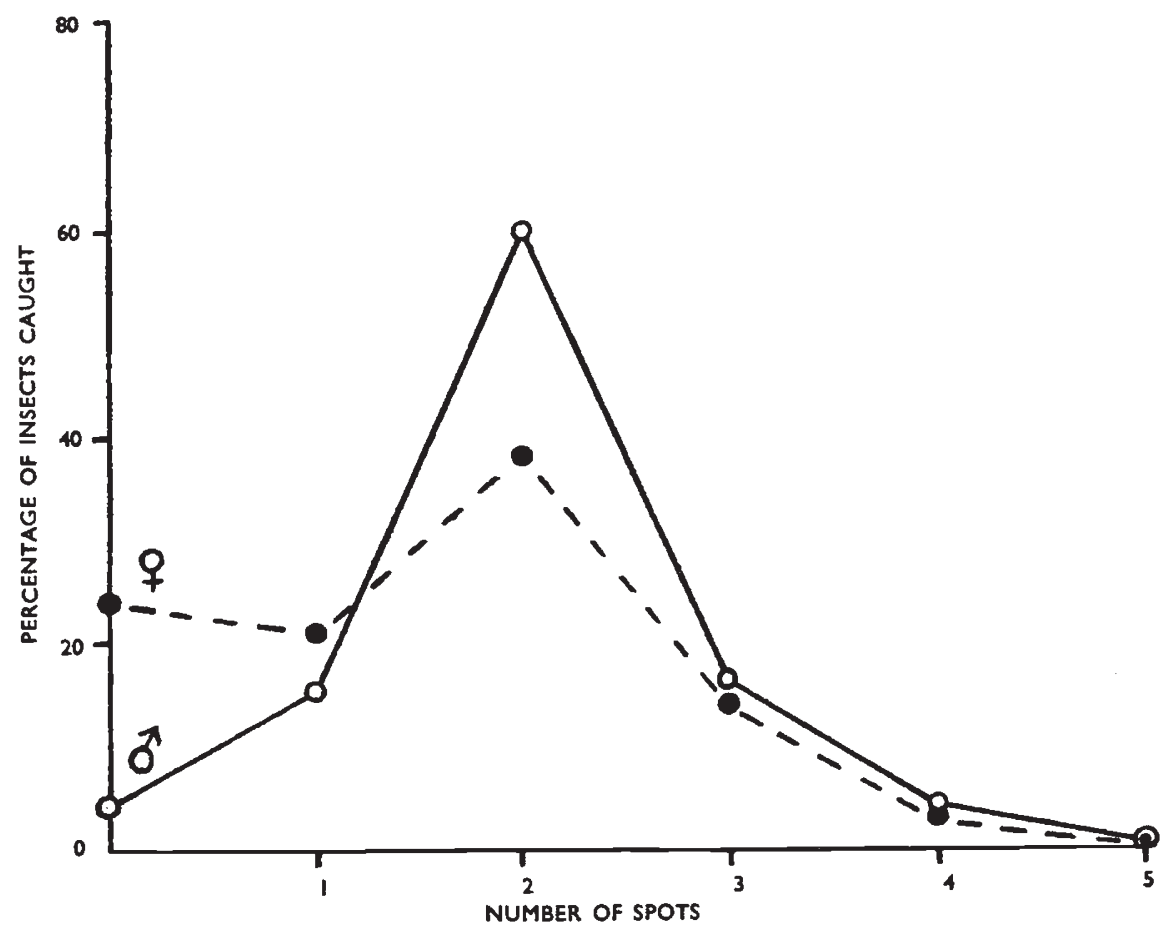

Fig. 2.

genetic type were responsible for the production of spotting in females but not in males: it may be that additional genes, sex-controlled in effect, inhibit spotting in the females.

The result is that, judged on these spot numbers, the female is the more variable sex. It is noteworthy that we have before obtained evidence of this tendency, though without indication of bimodality, in a survey of variability in ground-colour in 35 species of night-flying moths which two of us undertook in 1928 (3). In that sample, we found that the mean variance of the females is about 30 per cent. greater than that of the males. We showed that sex-linkage could not be responsible for this effect, but it has never been satisfactorily explained and deserves further investigation. The occurrence of greater female variability in 35 species of moths, and its reappear- 
ance in a somewhat different form in the present butterfly data, suggests that this may be a widespread phenomenon in the Lepidoptera.

\section{MIGRATION}

We saw numbers of butterflies crossing the sea from one island to another of the Scilly group but never observed $M$. jurtina doing so, and indeed there is no evidence that this is a migratory insect. However, we made a small-scale test to examine the matter somewhat further by experimental means.

On 26 th August we captured 46 specimens of $M$. jurtina on that part of the neighbouring island of St Martins where it approaches nearest to Tean. The intervening distance is here only about 300 yards, but the coasts fall sharply away from one another in either direction from that point. We gave these insects a distinguishing mark with red cellulose paint and liberated them again. This sample included none that had been taken on Tean, though we had during the previous ten days released 1003 marked specimens (omitting recaptures) there. Nor were any bearing the St Martins mark taken later on Tean among the 322 specimens (also omitting recaptures) which we caught during the remainder of our stay. On the whole it seems probable therefore that the migration of $M$. jurtina from one island to another is a rare event.

\section{NUMERICAL ANALYSIS OF THE THREE M. JURTINA POPULATIONS ON TEAN}

As already explained, we estimated the numbers of $M$. jurtina in each population on Tean by marking the specimens with dots of cellulose paint. These are permanent, for the paint is water-proof, and it dries in about ten seconds and seals the scales on to the wings. The position and colour of each spot indicates a date of capture. The specimens were put into separate boxes when caught and taken to one of our tents for marking and recording when the samples had been collected. They were subsequently set free at a releasing point in the centre of the area in which they had been captured.

The sizes of the daily samples which we aimed at collecting were 40 from area I, 6o from area 3 , and 20 from area 5. As already explained, areas 2 and 4 constitute barriers and were not populated by $M$. jurtina.

The insects were allowed at least two hours of active flight before a second sample was taken on the following day. Specimens belonging to the most recent sample were constantly found scattered in all directions from the releasing point up to the limits of each colony, for the habits of this butterfly make its distribution largely independent of the direction of the wind. The individuals tend to fly low across or against the wind, and at intervals to drift down with it at a slightly greater height. Moreover, we were careful to randomise our captures, 
taking them from all parts of each colony, and we did not find an undue proportion of those recently marked near the releasing points.

It was, however, necessary to guard against the possibility that specimens had been damaged in the marking and were unable to fly or to distribute themselves when released. For this purpose we decided to employ similar precautions to those adopted by Fisher and Ford (1947) in the work on Panaxia dominula. Any insects which had obviously been damaged were killed and recorded as such. The remainder were thrown high into the air when liberated. Those which fell without flying were examined and if they appeared undamaged were again thrown into the air. If they fell once more they too were killed and so entered in the records. An area of ro yards round each releasing point was not collected. This was inspected each day so that any specimens found within it could again be thrown into the air and then killed if they appeared unable to fly. However, $M$. jurtina proved particularly easy to handle without injury, and in fact we only damaged four specimens out of the 1569 which we caught.

The following is an analysis of our numerical data.

The abundance of the data available for $M$. jurtina, the frequency of the days of capture and release, and the distinction of the sexes of all insects captured allow of an examination of the course of change in the population in some respects more detailed than has been attempted on previous occasions.

The method of analysis is that set out in detail by Fisher and Ford (1947) in analysing several years' records of the moth Panaxia dominula, and need only be indicated summarily. From the known numbers marked and released on previous days, the number of marks on insects now probably alive and flying in the population available for sampling may be calculated, if the rate of daily elimination is known. An objective estimation of this rate of elimination is obtainable from the number of days between marking and recapture observed in the case of recaptures. Corresponding with any assumed rate of elimination we can, in fact, by direct arithmetic, make an estimate of the total number of days for all marks recaptured, and compare this with what has been observed.

Preliminary trials with the jurtina data indicated that in most cases a daily rate of elimination of i I per cent., corresponding with an expectation of life of eight days, resulted in a satisfactory agreement. Elimination was, however, certainly at a higher rate than this in the small region of area 5 , though the similar indication, for the females only, in area 3 is not trustworthy owing to the small nurinbers caught.

Before considering the special cases it will, however, be clearer if the results of using a single death rate be set out for all areas, and for the two sexes separately. The sex ratio has evidently changed greatly during the course of the sampling, and as it also shows considerable differences between different areas, the treatment of the 
females and males of each area as though they were two distinct populations is in this material particularly important.

The simplest record is that provided by area $\mathrm{I}$. With independent estimates of the numbers flying both of females and males it is possible to compare the values of the sex ratio at different dates, obtained

M. Jurtina, 1946, Area 1.

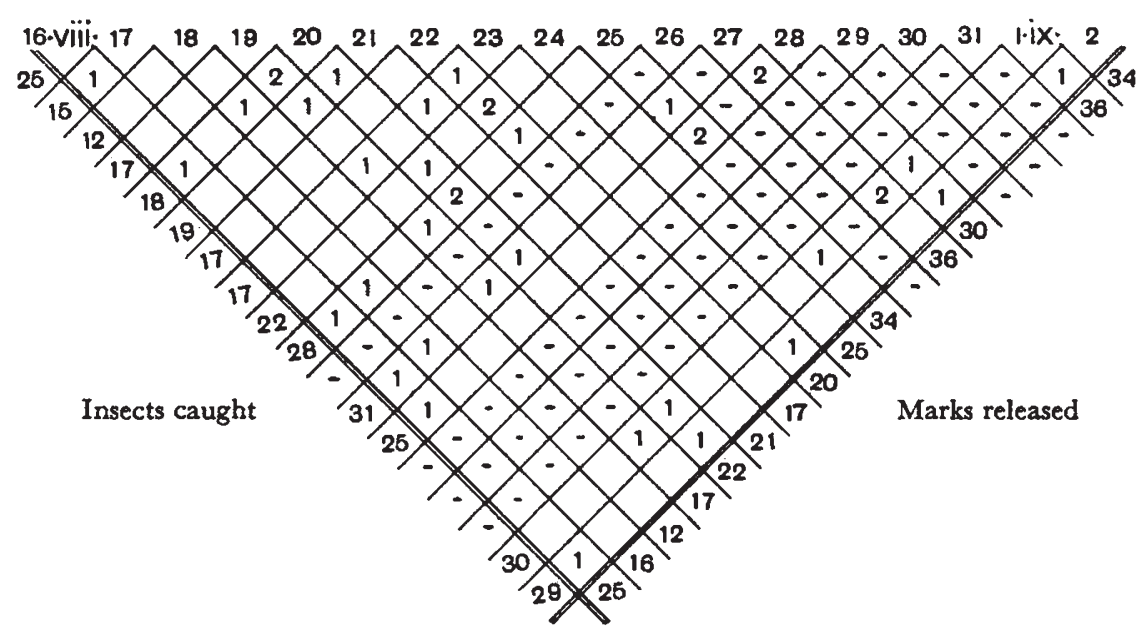

M. Jurtina, 1946. Area 1. d.

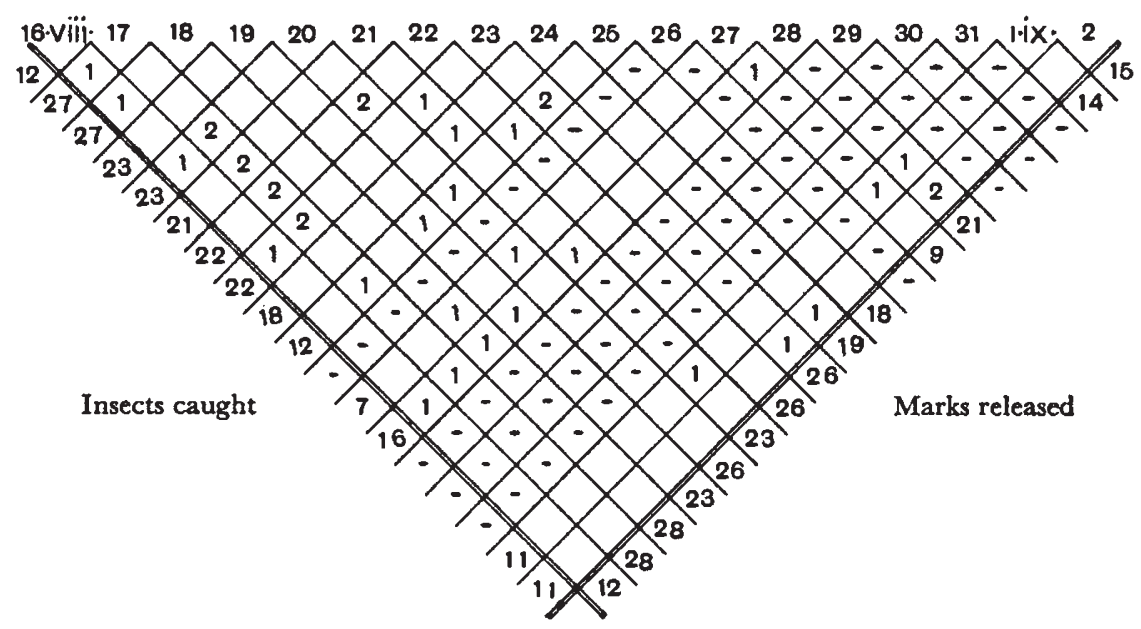

by two distinct methods : (i) from the numbers of insects of the two sexes caught on these dates, (ii) from the numbers estimated to be flying at these dates.

For area I, the number of marks estimated to be on females at large in the population had been built up to over 50 by the fourth day, igth August. It reached its peak at ${ }_{1} 6$ on 28th August. For males it was over $5^{\circ}$ by 18 th August, and was at its highest with 
II4 on 25th August. Through nearly the whole of the season, therefore, the population had been adequately marked, and each sample of 40 taken daily gave a good basis for estimating the numbers.

TABLE 3

Numbers and sex ratio at different dates in area $I$

\begin{tabular}{|c|c|c|c|c|c|c|}
\hline & \multicolumn{3}{|c|}{ Numbers captured } & \multicolumn{3}{|c|}{$\begin{array}{l}\text { Estimated numbers flying with } \\
89 \text { per cent. survival }\end{array}$} \\
\hline & Females & Males & $\begin{array}{c}\text { Males } \\
\text { per cent. }\end{array}$ & Females & Males & $\begin{array}{c}\text { Males } \\
\text { per cent. }\end{array}$ \\
\hline $\begin{array}{l}\text { August I } 7-20 \\
\text { August } 21-25 \\
\text { August } 27-28 \\
\text { September } 1-2\end{array}$ & $\begin{array}{r}62 \\
103 \\
56 \\
59\end{array}$ & $\begin{array}{r}\text { I0o } \\
95 \\
23 \\
22\end{array}$ & $\begin{array}{l}6 \mathrm{r} \cdot 7 \\
48 \cdot 0 \\
29 \cdot 1 \\
27 \cdot 2\end{array}$ & $\begin{array}{l}466 \cdot 2 \\
590 \cdot 0 \\
596 \cdot 0 \\
530 \cdot 1\end{array}$ & $\begin{array}{l}801 \cdot 3 \\
546 \cdot 6 \\
277 \cdot 2 \\
225 \cdot 4\end{array}$ & $\begin{array}{l}63 \cdot 2 \\
48 \cdot z \\
31 \cdot 7 \\
29 \cdot 8\end{array}$ \\
\hline
\end{tabular}

The good agreement between these two independent methods is perhaps connected with the apparent equality of the death rates. For females the total days exposure of the marks recaptured is 213 against 196.8 expected, while for males it is 200 against 186.4 .

On reworking with a daily elimination of only 7 per cent., or an expectation of life of 13.3 days, the expectation for males is quite close, $198^{\circ} 0$, to the observed 200 , while that for females is even closer, 213.3 against 213. Such an estimate of the death rate based on a single year's observation in a single area cannot of course, have any great precision. Since, however, it is not impossible a priori, though the view receives no support from other areas, that the expectation of life is greater than a fortnight, it is instructive to recalculate the estimated numbers flying on this basis. We then have

TABLE 4

Estimated numbers flying in area 1 , with daily elimination of only 7 per cent.

\begin{tabular}{|c|c|c|c|c|}
\hline & & Females & Males & Males per cent. \\
\hline $\begin{array}{l}\text { August I 7-20 } \\
\text { August } 21-25 \\
\text { August } 27-28 \\
\text { September I-2 }\end{array}$ & $: \quad:$ & $\begin{array}{l}510 \cdot 6 \\
697 \cdot 6 \\
751 \cdot 0 \\
746 \cdot 3\end{array}$ & $\begin{array}{l}866 \cdot 2 \\
638 \cdot 5 \\
367 \cdot 3 \\
343 \cdot 6\end{array}$ & $\begin{array}{l}62 \cdot 9 \\
47 \cdot 8 \\
32 \cdot 8 \\
31 \cdot 5\end{array}$ \\
\hline
\end{tabular}

The estimated numbers are appreciably greater, especially towards the end of the season : but the sex ratio is scarcely changed. Males are falling in numbers for the whole period, while the maximum abundance of females is near to the end of August. The total population in the area probably never falls outside the limits 750-1400. 
Area 5, with a very small population, of the order of 100 compared with 1000 in area 1 , was extremely intensively studied with a sample of 20 on each day, except the last, ist September, when a large part of the available population must have been taken in the sample of 16 recorded.

M. Jurtina, 1946. Area 5. ㅇ.

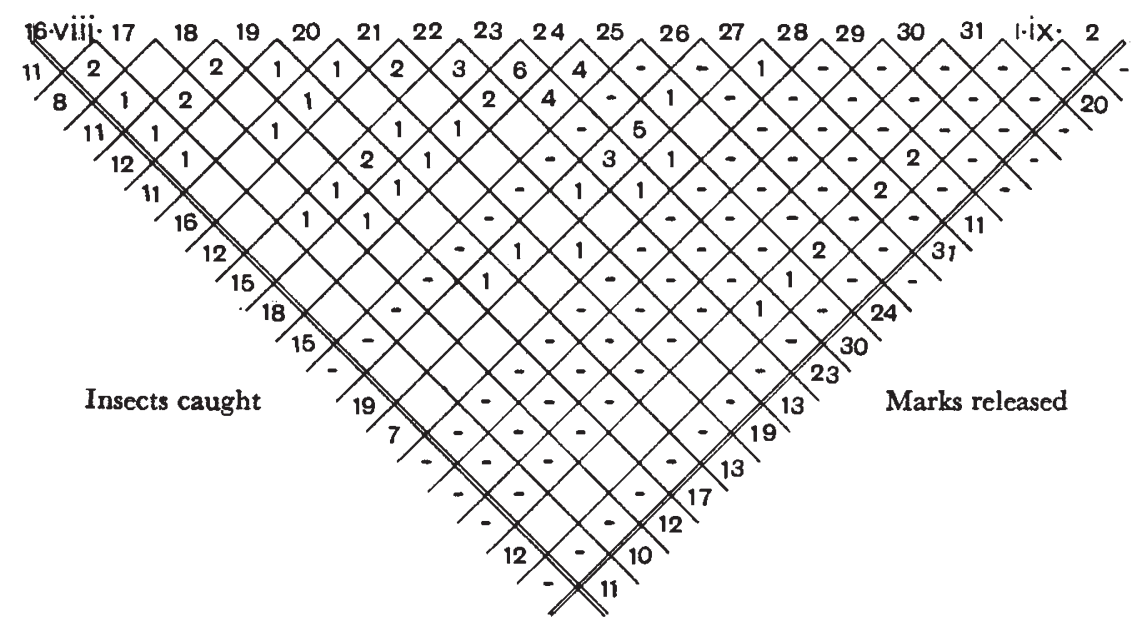

M. Jurtina, 1946. Area 5. đ.

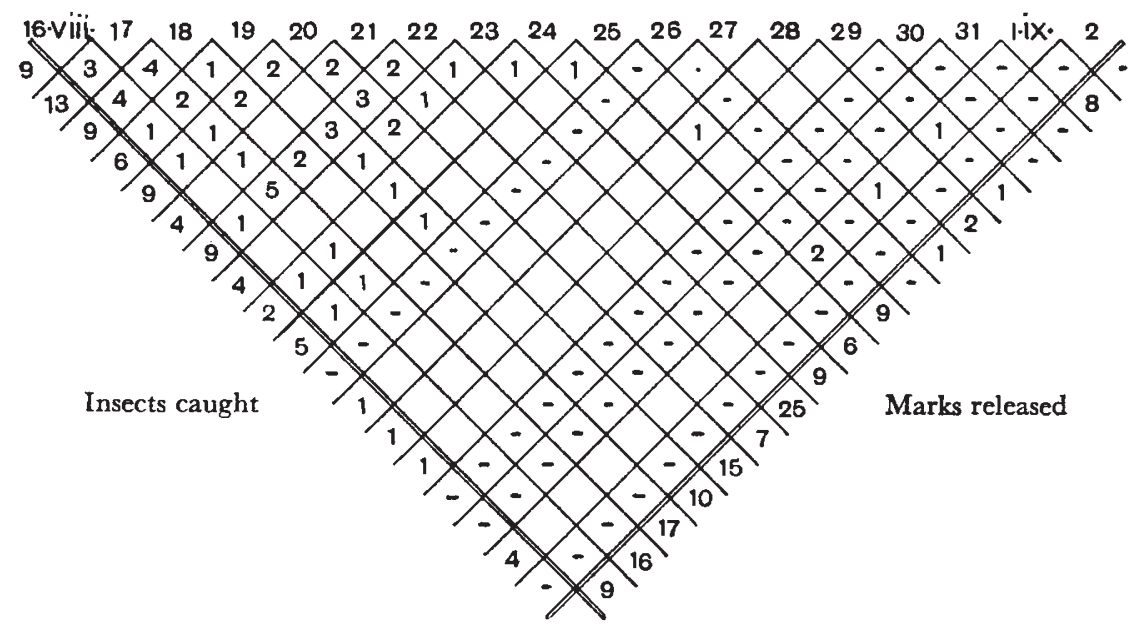

Here, on internal evidence, the death rate was higher in both sexes than the II per cent. daily elimination taken as standard. The sex ratio was also appreciably lower, nearly three times as many females as males being taken in all.

At the death rate assumed, the expected total of days exposure to risk of marks recaptured is 278.5 for females against 207 observed, and 202.0 for males against 181 . The death rate assumed appears 
to overestimate the chances of survival of both males and females, and this perhaps is responsible for the anomalous feature in the table

TABLE 5

Numbers and sex ratio at different dates, area 5

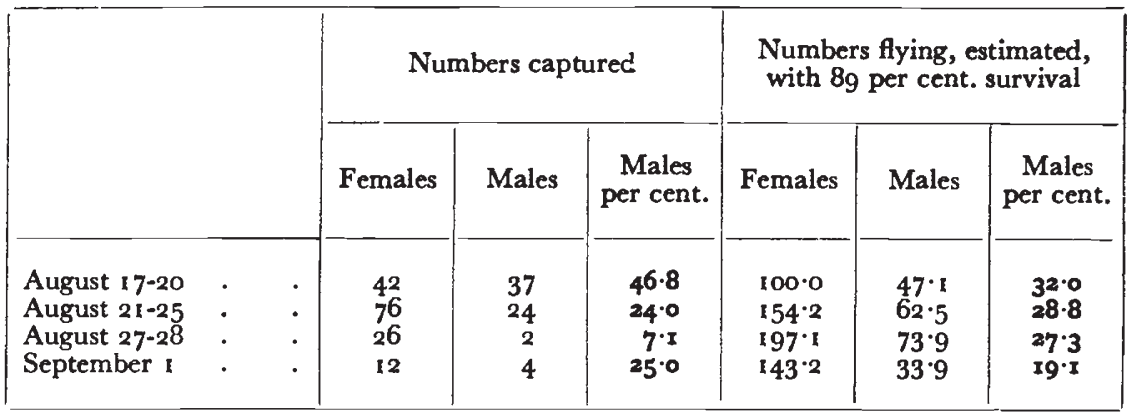

above, in which the males are given an apparent increase in absolute numbers up to the end of August, whereas it is more probable that, as in area $\mathrm{I}$, they were really decreasing.

If the estimates are recalculated with 25 per cent. daily elimination, or an expectation of life of only three days, we find

TABLE 6

Numbers flying estimated with 75 per cent. survival, area 5

\begin{tabular}{|c|c|c|c|c|}
\hline & & Females & Males & Males per cent. \\
\hline $\begin{array}{l}\text { August 1 } 7-20 \\
\text { August } 21-25 \\
\text { August } 27-28 \\
\text { September } 1\end{array}$ & $\begin{array}{l}\dot{.} \\
\dot{ } \\
\dot{ }\end{array}$ & $\begin{array}{l}67 \cdot 1 \\
75 \cdot 6 \\
53 \cdot 2 \\
21 \cdot 6\end{array}$ & $\begin{array}{r}23 \cdot 4 \\
13 \cdot 7 \\
20 \cdot 6 \\
3 \cdot 3\end{array}$ & $\begin{array}{l}25 \cdot 9 \\
15 \cdot 4 \\
28 \cdot 0 \\
13 \cdot 1\end{array}$ \\
\hline
\end{tabular}

For males the days exposure of marks recaptured now agrees well with the observed 183.2 against $18 \mathrm{r}$, though it is still a trifle too high ; for females it is still materially high, 228.0 against 207.

That it would not be reasonable to assign a still shorter life, at least to the males in this area, is shown by the calculated number flying on ist September having fallen to 3.3 whereas actually 4 were taken. Only 12 females, however, were taken and perhaps there were not so many as 22 available for capture. The suggestion that the female death rate was higher than the male seems paradoxical for this area, where only 30 per cent. of the captures were of males. The expected proportion is, however, only 26.3 per cent. at in per cent. daily elimination, and only 21.9 per cent. at 25 per cent. daily loss. Consequently, a somewhat more rapid elimination of females would somewhat improve the agreement with the sex ratios of insects captured. 
The population of area 3 was so great that even the allowance of 60 insects to be caught daily led to very few recaptures of marked specimens. Consequently, the internal evidence of survival rate is

M. Furtina, 1946. Area 3. ㅇ.

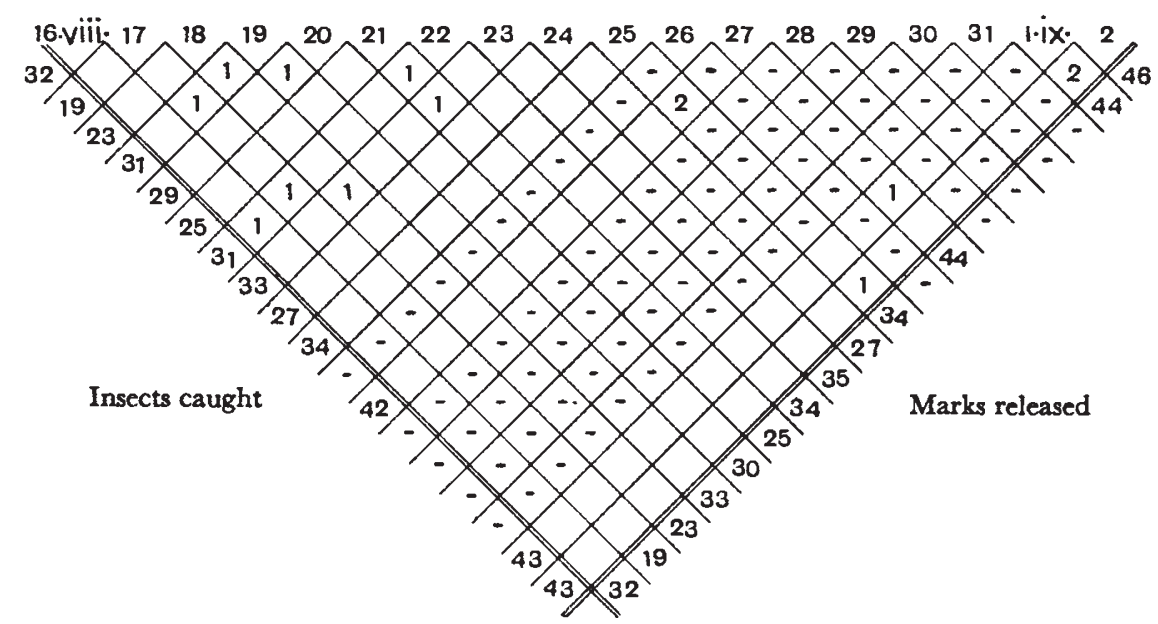

M. Jurtina, 1946. Area 3. 0 .

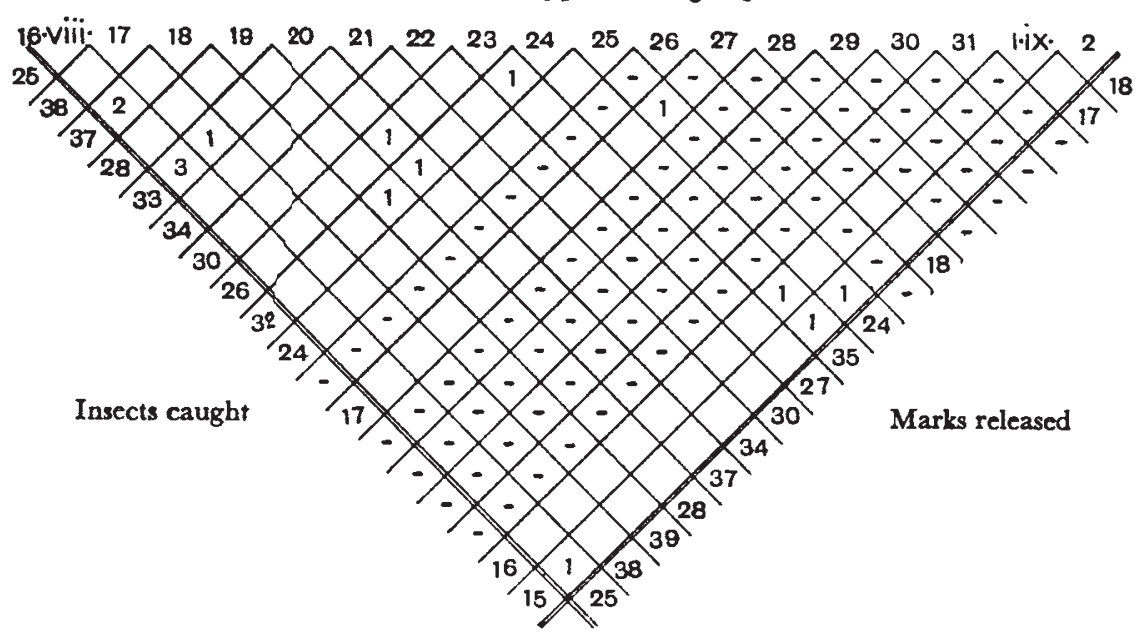

here weak, and no stress can be laid on the striking deficiency in the apparent longevity of the females. Working at in per cent. daily elimination we obtain the results shown in table 7 .

For nales the total days exposure of the marks recaptured was 76 against $72 \cdot 64$ expected, the death rate assumed thus seems nearly right for males, if anything too high. The total number may therefore have exceeded a maximum of 2500. For females there is a disconcerting discrepancy in that only forty-two days exposure was observed against $65^{\circ} \circ$ expected. The marks recaptured were, however, 
only 14 in all, so that it may well be by chance that most of them had been released only a few days previously. A much higher death rate

TABLE 7

Numbers and sex ratio at different dates in area 3

\begin{tabular}{|c|c|c|c|c|c|c|}
\hline & \multicolumn{3}{|c|}{ Numbers captured } & \multicolumn{3}{|c|}{$\begin{array}{c}\text { Estimated numbers flying with } \\
89 \text { per cent. survival }\end{array}$} \\
\hline & Females & Males & $\begin{array}{c}\text { Males } \\
\text { per cent. }\end{array}$ & Females & Males & $\begin{array}{l}\text { Males } \\
\text { per cent. }\end{array}$ \\
\hline August $17-20$ & 102 & 136 & $57 \cdot 1$ & $1870 \cdot 9$ & $1259 \cdot 4$ & $40 \cdot 2$ \\
\hline August 21-25 & 150 & $\begin{array}{l}340 \\
146\end{array}$ & 50.7 & $466 \mathrm{r} \cdot 2$ & $\begin{array}{r}256 \mathrm{I} \cdot 8 \\
25\end{array}$ & $\begin{array}{l}40.2 \\
35.5\end{array}$ \\
\hline August 27 & 42 & i7 & $28 \cdot 8$ & $3030 \cdot 3$ & $253^{1} \cdot 3$ & $45 \cdot 5$ \\
\hline September I-2 & 86 & $3^{i}$ & $26 \cdot 5$ & $25^{2} 5^{\circ} \mathrm{O}$ & $733 \cdot I$ & $22 \cdot 5$ \\
\hline
\end{tabular}

for the females than that assumed would imply a smaller female population, and a higher sex ratio, especially at the later dates. The sex ratio of the actual captures does not favour this view, nor the observed sex ratios in the other areas.

\section{DISCUSSION}

It will be seen from the foregoing analysis that the populations of $M$. jurtina on Tean differ markedly from one another in total numbers. The largest numbers flying on any one day being : area $\mathrm{I}$, about 1400 ; area III, about 7000 ; and Area V, probably less than 250 and perhaps no more than Ioo. It is a difficult matter to pass from a series of daily estimates to the evaluation of the total number of individuals in a population throughout the season. The total emergences can, however, scarcely be less than twice the maximum number observed on any one day, and are not likely to be so much as five times this number. At any rate, it appears that the whole population in area I considerably exceeds 3000 , that in area III it exceeds 15,000 , while in area $\mathrm{V}$ it cannot easily exceed 500 .

It is valuable to compare observed survival-rate with that expected on the assumption of a uniform amount of elimination, for this provides a standard of comparison between different populations. The daily elimination of I I per cent. may best be used for this purpose. The result is given in table 8 in which, for each population, observation is divided by expectation and expressed as a percentage.

It will be convenient first to consider the two areas which were sampled sufficiently thoroughly to provide trustworthy results: these are I and V. In both sexes the daily elimination rate is markedly higher in the smaller area $\mathrm{V}$ than in the larger area $\mathrm{I}$.

Area I is approximately 170 by 130 yards and harboured about 1400 individuals at the maximum, while area $\mathrm{V}$ is approximately 
I 50 by 65 yards with a maximum population of less than 250. Thus it will be noticed that the population is relatively denser in area I. This is probably connected with the fact that the opportunities for

TABLE 8

Percentages observed compared with expected survival at II per cent. daily elimination [being, (observation-expectation) per cent.]

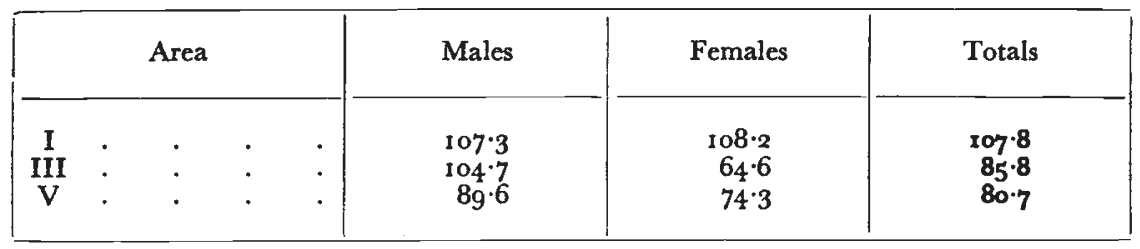

sheltered flight in bad weather will on the average be better in a large than in a small, and probably less diversified, area. This consideration will not only tend to reduce the relative size of the population which a small area can support but also to shorten the average expectation of life of the individuals composing it.

Moreover, the chances of a butterfly straying and being lost, or of being blown away, are considerable when it is close to the edge of a colony but much smaller when well within it. All parts of area $\mathrm{V}$, which is small and narrow, are probably dangerous from this point of view, while a fraction only of the larger and squarer area I will be so. This effect also will reduce the average length of life of $M$. jurtina in area $\mathrm{V}$ compared with area I.

The survival of the two sexes is almost equal in area I, but that of the males appears to be somewhat superior in area V. The significance of this is not very clear, but the females are the larger and fly less powerfully. It is possible therefore that they may more frequently be blown away from the relatively exposed area $\mathrm{V}$.

As indicated in the last section, unlike areas I and V, the population in area III was very imperfectly sampled. Owing to its great size, the number of recaptures has proved too small to provide the necessary data even though we marked 60 specimens per day. The close agreement between the survival-rate of males in this area and in area I, where the population also much exceeds Iooo, certainly suggests that the elimination is approximately equal in these larger areas. However, as explained on p. 79, no significance can be attached to the very low survival rate of the females in area III since only I4 marks (and specimens, for none of these insects was caught three times) were recaptured. Consequently a chance excess of butterflies recently marked could easily occur and would give the appearance of a high rate of elimination. It will be noticed that none of the results for areas $\mathrm{I}$ and $\mathrm{V}$ is based upon less than 37 marks recaptured, so that the average time interval between marking and recapturing is tolerably well established. 
There is moreover direct evidence for believing that the eliminationrate of females in area III is not unduly high. It must be emphasised that, as shown in section 6 , the comparisons between the calculated sex-ratios and those actually observed provide a valuable independent check on our estimates. It will have been noticed that the observed and calculated sex ratios are, in general, in good agreement, while the observed sex-ratio in area III does not suggest a much greater elimination of females than of males; were the female elimination relatively great, the sex-ratio would be higher, especially at the later dates.

Our failure to obtain an adequate sample of the very large population in area III is of importance for the general theory of population sampling. The larger a population may be, the more difficult it becomes to mark enough specimens to obtain a sufficiency of recaptures. The recovery of but few marked individuals may indeed provide a fair general indication of the size of a population, as it has done in this instance, but not of its more detailed properties such as the elimination-rate to which it is exposed. At the other extreme, a very small population cannot easily be sampled owing to the difficulty of capturing enough specimens, marked or unmarked, for the purpose. There is thus an optimum range of population-size for such studies. When engaged in work of this kind, the investigator will have to modify the size of his samples in the light of his results as he proceeds, so as to ensure an adequate recovery of marks. This might prove impracticable in a very large population.

In our work on the moth Panaxia dominula (2) we produced evidence to show that chance fluctuations in gene-ratio do not control the evolution of isolated populations of about 1000 or more. On the other hand, though the effects of random survival may be of some importance in populations smaller than this, we suggested that small isolated populations will usually become extinct in periods of time which must be extremely short from an evolutionary point of view.

The present study of Maniola jurtina is relevant to this conclusion. We are here able to make sufficiently accurate comparisons of two populations whose approximate size is known; one of above 3000 individuals and one which cannot easily exceed 50o. The survivalrate proves to be substantially less in the smaller of them, and this is true for both sexes when treated as separate populations within each colony. Consequently it seems likely that this butterfly would not maintain itself in area $\mathrm{V}$ were it not recruited by some leakage of specimens from area III across the barrier presented by area IV.

Small, compared with large, isolated populations are subject to disadvantages of several kinds. Some of these are due to the fact that numerically small colonies tend to occupy areas of less extent than large ones, while several other handicaps from which they suffer 
are not dependent upon the size of the inhabited territory. As already suggested, loss from the relatively great perimeter of a small area probably constitutes a serious menace to such forms as Lepidoptera in an exposed situation, as in area $\mathrm{V}$ on Tean. Yet it may be of negligible significance in ecological conditions of a different kind; for instance, those experienced by mice in a wood. On the other hand, the less diversified nature of small than of large habitats is a danger of more general application. Among the defects inherent in small populations irrespective of the size of the territory they colonise, two may be mentioned here: the dangers which sometimes result from inbreeding and those which arise from fluctuation in numbers. This latter consideration is of great importance. Such fluctuations are very usual in animal communities, and though they may be safely tolerated by a large population they may reduce a small one to such a low level that recovery becomes difficult or impossible.

There are thus several tendencies which all contribute to make quite small isolated populations, those of materially less than 1000, impermanent units. Yet it is in them alone, not in those of larger size, that chance fluctuations in gene-ratio could possibly contribute to evolutionary change, even if the great difficulties to believing that they would in fact do so, could be set aside.

\section{SUMMARY}

I. We have studied three populations of the butterfly Maniola jurtina on the Island of Tean, Isles of Scilly.

2. These populations are isolated by minor ecological barriers. The amount of interchange between them was determined by marking methods and found to be small.

3. The migration of this butterfly from one island to another appears to be rare, a conclusion confirmed also by marking methods.

4. A quantitative character, spot-number on the hind wings, was studied to determine whether the three populations had diverged measurably in isolation. No indication of this was found. The distribution of these spots proved to be exceptional, being unimodal in the male but bimodal in the female (the heterozygous sex).

5. Judged on spot-number, the female is the more variable sex. Greater female variability has also been detected in the Lepidoptera on a previous occasion : in a survey of 35 species of night-flying moths conducted by two of the authors twenty years ago.

6. The three colonies of $M$. jurtina occupied areas which are severally large (area III), intermediate in size (area I), and small $($ area $\mathrm{V})$ : see map.

7. The number of individuals in these populations was estimated by the method of marking, release, and recapture.

8. The total emergence in area III exceeded 15,000 , in area I it exceeded 3000 , while in area $\mathrm{V}$ it could not much exceed 500. 
9. A life-table, giving daily elimination-rates, was calculated for each sex in each population.

Io. The data obtained in areas I and V supplied a satisfactory basis for this work, but the recaptures in the largest population were too few to provide corresponding evidence for area III.

I I. The survival-rate proved to be substantially less for the population of about 500 (in area V) than for that exceeding 3000 (in area I). This applied to both sexes when treated as separate populations within each colony.

I2. An independent check upon these estimates is provided by the comparison between the calculated sex-ratios and those actually observed at different dates.

I3. The probability that populations much below rooo frequently become extinct is considered both theoretically and in the light of these data, and its bearing upon evolutionary theory is pointed out.

\section{REFERENCES}

1. DOWDESWELL, W. H., FISHER, R. A., AND FORD, E. B. 1940.

The quantitative study of populations in the Lepidoptera.

1. Polyommatus icarus Rott.

Ann. Eugen. 10, 123-136.

2. FTSHER, R. A., AND FORD, E. B. 1947.

The spread of a gene in natural conditions in a colony of moth Panaxia dominula $\mathrm{L}$.

Heredity $I, 143-174$.

3. FISHER, R. A., AND FORD, E. B. 1928.

The variability of species in the Lepidoptera with reference to abundance and sex.

Trans. Ent. Soc. Lond., 76 367-384. 